\title{
Le chant du rossignol. Sciences, pratiques sociales et représentations dans le temps et l'espace
}

Rencontre. Bibracte (Glux-en-Glenne), 22-24 mai 2013

\section{Corinne Beck et Martine Clouzot}

\section{(2) OpenEdition}

\section{Journals}

Édition électronique

URL : https://journals.openedition.org/cem/13015

DOI : $10.4000 /$ cem. 13015

ISSN : 1954-3093

Éditeur

Centre d'études médiévales Saint-Germain d'Auxerre

Référence électronique

Corinne Beck et Martine Clouzot, « Le chant du rossignol. Sciences, pratiques sociales et

représentations dans le temps et l'espace », Bulletin du centre d'études médiévales d'Auxerre | BUCEMA

[En ligne], 17.1 | 2013, mis en ligne le 28 mai 2013, consulté le 22 septembre 2022. URL : http:// journals.openedition.org/cem/13015; DOI : https://doi.org/10.4000/cem.13015

Ce document a été généré automatiquement le 22 septembre 2022.

\section{(c) (i) (2) (2)}

Creative Commons - Attribution - Pas d'Utilisation Commerciale - Partage dans les Mêmes Conditions 4.0 International - CC BY-NC-SA 4.0

https://creativecommons.org/licenses/by-nc-sa/4.0/ 


\section{Le chant du rossignol. Sciences, pratiques sociales et représentations dans le temps et l'espace}

Rencontre. Bibracte (Glux-en-Glenne), 22-24 mai 2013

Corinne Beck et Martine Clouzot

1 «Les oiseaux chanteurs » est un projet pluridisciplinaire, transversal et international initié et porté par l'UMR ARTeHIS 6298 de l'Université de Bourgogne et l'EA Calhiste de l'Université de Valenciennes. Ce projet consiste à élargir une thématique déjà étudiée par les ornithologues, les éthologues, les littéraires et les musicologues, à d'autres

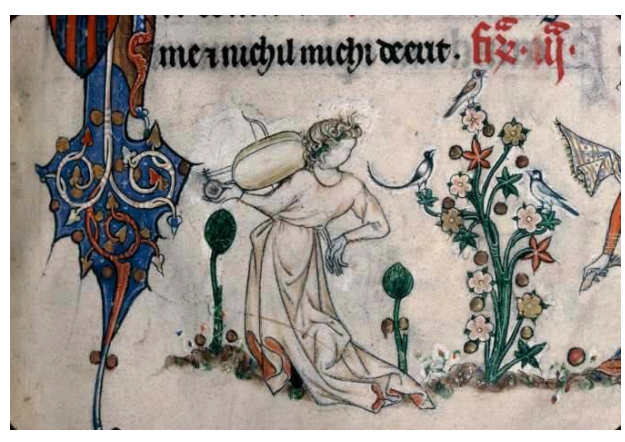
disciplines a priori éloignées, dont les problématiques centrales touchent essentiellement aux domaines des sciences du vivant, de l'environnement et des sciences humaines et sociales.

2 Le projet est initié et porté par Corinne Beck, historienne et archéologue médiéviste (prof. à l'Université de Valenciennes) et Martine Clouzot, historienne médiéviste (prof. à l'Université de Bourgogne).

3 S'inscrivant à la croisée des sources et des regards scientifiques, ce colloque cherche à mettre en présence des chercheurs issus d'horizons disciplinaires fort divers et éloignés, tant des sciences humaines et sociales que des sciences de la vie, intéressés par les différentes définitions des « chants » des oiseaux, en vue de construire un objet de recherche commun.

4 L'objectif est de faire dialoguer dans l'interdisciplinarité anthropologues, ornithologues, éthologues, archéologues, environnementalistes, littéraires, linguistes, 
philologues, historiens, historiens de l'art, psychologues de la musique et de la cognition, musicologues.

5 Le principe retenu est la mise en commun des termes, des conceptions, des perceptions, et des problématiques à la fois transversales au sujet, et propres à chacune des disciplines, afin de privilégier les échanges et les collaborations scientifiques entre les chercheurs, entre les disciplines, entre les universités et les centres de recherches des différents pays.

\section{AUTEURS}

\section{CORINNE BECK}

Université de Valenciennes (Ea Calhiste)

MARTINE CLOUZOT

Université de Bourgogne (Umr Artehis) 